\title{
Leptin, MUC2 and mTOR in Appendiceal Mucinous Neoplasms
}

\author{
Mee Soo Chang a,b Sun-ju Byeon ${ }^{a, b}$ Sun Och Yoon ${ }^{a, b}$ Baek-hui Kimª \\ Hye Seung Lee ${ }^{b, c}$ Gyeong Hoon Kang ${ }^{b}$ Woo Ho Kim ${ }^{b}$ Kyu Joo Park ${ }^{d}$

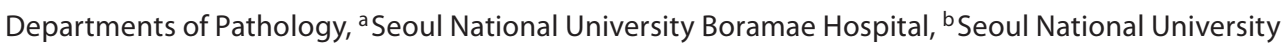 \\ College of Medicine, and ' Bundang Seoul National University Hospital, and ${ }^{\mathrm{d}}$ Department of Surgery, \\ Seoul National University College of Medicine, Seoul, Korea
}

\section{Key Words}

Appendiceal mucinous neoplasm $\cdot$ Leptin $\cdot$ MUC2 $\cdot$

$\mathrm{MUC} 5 \mathrm{AC} \cdot \mathrm{mTOR} \cdot \mathrm{STAT} 3 \cdot \mathrm{ERK}$

\begin{abstract}
Objective: Leptin contributes to mucin production in colonic epithelium and regulates carcinogenesis via various signalling pathways. We evaluated the proteins involved in mucin-producing carcinogenesis and putative targets for molecular therapy in appendiceal mucinous neoplasms. Methods: Immunohistochemistry and fluorescence in situ hybridization were performed in 22 cases of appendiceal mucinous adenoma, 20 mucinous neoplasms of uncertain malignant potential and 14 mucinous adenocarcinomas. $R \boldsymbol{e}$ sults: Leptin, MUC2, MUC5AC, mTOR and ERK were more frequently immunopositive in mucinous adenocarcinomas compared with mucinous adenomas or mucinous neoplasms of uncertain malignant potential $(p<0.05)$. STAT3 revealed immunopositivity in $82 \%$ of tumours, regardless of tumour category. MUC2 immunopositivity was associated with pseudomyxoma peritonei $(p<0.05)$. None of the tumours exhibited c-kit immunoexpression, amplification of Her2 or EGFR, or translocation of ALK. The mTOR-immunopositive group of patients had a lower rate of disease-free
\end{abstract}

\section{KARGER}

Fax +4161306 1234 E-Mail karger@karger.ch www.karger.com

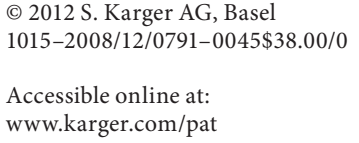

survival compared with the mTOR-immunonegative group $(p<0.05)$. Conclusions: Leptin may collaborate with MUC2 and MUC5AC in mucin-producing carcinogenesis in an mTOR-, STAT3- and ERK-dependent manner. STAT3 may be activated early during tumorigenesis. MUC2 and mTOR (but not c-kit, Her2, EGFR and ALK) may represent targets for molecular therapy in pseudomyxoma peritonei and appendiceal mucinous adenocarcinoma, respectively.

Copyright $\odot 2012$ S. Karger AG, Basel

\section{Introduction}

Appendiceal tumours are rare, constituting $0.4 \%$ of all intestinal neoplasms [1]. Some of their histopathological features resemble those of neoplasms of the small and large intestine; however, there are distinct differences between appendiceal tumours and other gastrointestinal tract tumours in terms of mucinous type. First, the pathological decision regarding the benignity or malignancy of appendiceal mucinous neoplasms is a challenging task

M.S.C. and S.B. contributed equally to this study.
Mee Soo Chang, MD, PhD

Department of Pathology, Seoul National University Boramae Hospital

41 Boramae-gil, Dongjak-gu

Seoul 156-070 (Republic of Korea)

Tel. +82 2870 2641, E-Mail meesooch@snu.ac.kr 
as cellularity tends to be extremely low, cytoarchitecture bland looking, and, which is worse, fibrotic appendiceal walls and disappearance of muscularis mucosae occur commonly; hence, it is difficult to assess tumour invasion. Second, appendiceal mucinous neoplasms sometimes cause a clinical condition termed 'pseudomyxoma peritonei', in which mucinous neoplasms extend to the peritoneum beyond the right lower quadrant, with vast amounts of voluminous and gelatinous mucin.

The pathological classification of appendiceal mucinous neoplasms has been debated, and Carr et al. [2], Misdraji et al. [3] and Pai et al. [4] have proposed diagnostic classifications. In 2010, the IARC/WHO Committee has described only mucinous adenocarcinoma of the appendix but has not covered the entire spectrum of mucinous neoplasms [5]; thus, the classification of appendiceal mucinous neoplasms is still controversial. In the present study, we adopted the three-tiered categories of Carr et al. [2], i.e. mucinous adenoma, mucinous neoplasm of uncertain malignant potential and mucinous adenocarcinoma of the appendix, since this classification was supported by clinical outcome and analysis of protein alteration in our previous report [6]. Moreover, we adopted the term 'appendiceal mucinous neoplasm of uncertain malignant potential' from Carr et al. [2], and followed the criteria revisited by Pai et al. [4]. We strictly defined 'appendiceal mucinous neoplasm of uncertain malignant potential' in the present study as follows: under the condition of lost muscularis mucosae or undiscerned individual layers of the appendix (accordingly, 'undetermined invasion'), appendiceal mucinous neoplasms display a bland cytoarchitecture, but the features show (1) epithelium pushing deeply into underlying tissue, (2) a cystic gland-like structure in the appendiceal wall or (3) uncertainty of complete excision, such as a positive proximal margin or extensive mucin on the appendiceal serosa [6].

Pseudomyxoma peritonei is recognized as a neoplastic and progressive condition [3-9]. Appendiceal mucinous neoplasm is accepted as the primary culprit for pseudomyxoma peritonei, and the classification of appendiceal mucinous neoplasm has been additionally complicated by pseudomyxoma peritonei [3-9]. Moreover, there is no standardized treatment for patients with pseudomyxoma peritonei, which often culminates in the demise of these patients, despite the many modalities of treatment, such as repeated debulking surgery, intraperitoneal chemotherapy and systemic chemotherapy [8-10].

To date, the mechanism underlying the production of vast amounts of mucin (pseudomyxoma peritonei) ob- served in appendiceal mucinous neoplasms remains unknown. According to a recent study, leptin contributes to mucin production in colonic epithelial cells, and a leptininduced increment of mucins, such as MUC2, MUC5AC and MUC4, has been reported $[11,12]$. We had previously reported that MUC2 and MUC5AC were related to the malignant behaviour of appendiceal mucinous neoplasms [6]. Recently, leptin was identified as multifunctional, i.e., it not only controls food intake and energy balance [13], but it also regulates carcinogenesis [14-16] and inflammatory processes [17]. The function of leptin is mediated by the leptin receptor. Leptin activates multiple signalling molecules, including the mammalian target of rapamycin (mTOR), the signal transducer and activator of transcription 3 (STAT3), the extracellular cellular-regulated kinase (ERK), the mitogen-activated protein kinase (MAPK) and the phosphatidylinositol 3-kinase (PI3K) [12, 18-20]. These signalling pathways play a key role in various types of cancer, in terms of cell growth and apoptosis [18, 19, 21].

The present study focused on leptin, the leptin receptor, MUC2, MUC5AC, mTOR, STAT3 and ERK to investigate the molecular pathways involved in mucin-producing carcinogenesis, followed by the assessment of putative targets for molecular therapy, such as the mTOR, c-kit, human epidermal growth factor receptor 2 (HER2/neu), epidermal growth factor receptor $(E G F R)$ and anaplastic lymphoma receptor tyrosine kinase $(A L K)$ genes.

\section{Materials and Methods}

Patients and Tissue Samples

We selected 56 cases of appendiceal mucinous neoplasms from our previous report [6]. Therefore, the present study included 22 mucinous adenomas, 20 mucinous neoplasms of unknown malignant potential and 14 mucinous adenocarcinomas resected from 1998 to 2007 at three hospitals affiliated with the Seoul National University Hospital. The follow-up period was 12-60 months for malignant cases and 7-120 months for the remaining cases. The histology of all cases was reviewed by 3 pathologists (S.B., S.O.Y. and M.S.C.). The study protocol was reviewed and approved by the Institutional Review Board of the Seoul National University Boramae Hospital (IRB No. 20100527/06-2010-67/96).

\section{Tissue Array Methods}

Two to nine different representative areas per case were selected for further analysis. Each tissue core $(2.0 \mathrm{~mm}$ in diameter) was punched out from the selected area in the original paraffin block of tumour samples using a trephine apparatus (Superbiochips Laboratories, Seoul, South Korea). The punched cores were arranged in a new tissue array paraffin block containing 59 tissue cores and one ink core, used as a direction indicator. Eventually, six tissue array blocks (360 cores) were newly prepared, including 
Table 1. Antibodies used for immunohistochemical staining

\begin{tabular}{llll}
\hline Antibody & $\begin{array}{l}\text { Expression in } \\
\text { tumour cells }\end{array}$ & Dilution & Source $^{\text {a }}$ \\
\hline Leptin/Ob (A-20) & cytoplasm & $1: 50$ & $\begin{array}{c}\text { Santa Cruz } \\
\text { Leptin receptor/Ob-R (B-3) }\end{array}$ \\
MUC2 (Ccp58) & membrane & $1: 25$ & Santa Cruz \\
MUC5AC (CLH2) & cytoplasm & $1: 100$ & Novocastra \\
Phospho-mTOR (Ser2448) (49F9) & cytoplasm & $1: 100$ & Novocastra \\
Phspho-p44/p42 MAPK (Erk1/2) (Thr202/Tyr204) (D13.14.4E) & nucleus & $1: 50$ & Cell Signaling \\
Phospho-Stat3 (Tyr705) (D3A7) & nucleus & $1: 50$ & Cell Signaling \\
c-kit (A4502) & cytoplasm & $1: 200$ & Dako \\
\hline
\end{tabular}

a Santa Cruz (Santa Cruz, Calif., USA), Novocastra (Newcastle Upon Tyne, UK), Cell Signaling (Danvers, Mass., USA), Dako (Carpinteria, Calif., USA).

56 cases of appendiceal mucinous neoplasms and 27 non-neoplastic appendiceal tissues (as controls).

\section{Immunohistochemistry}

Immunohistochemical staining was performed on a Benchmark XT instrument (Ventana Medical Systems, Tucson, Ariz., USA). Briefly, 3 - $\mu \mathrm{m}$-thick paraffin-embedded tissue sections of each study case were cut onto electrostatically charged glass slides. The BenchMark XT automated stainer tasks included online deparaffinization and antigen retrieval. Antigen detection was performed using iVIEW DAB (Ventana Medical Systems) and an ultraView Universal DAB Detection Kit (Ventana Medical Systems). Hematoxylin II (Ventana Medical Systems) was used as the counterstain. The primary antibodies used and the corresponding dilution ratios are listed in table 1.

Leptin and leptin-receptor staining were scored as follows: 0 (negative), no appreciable tumour cells; $1+$, weak staining in the cytoplasm of some tumour cells; $2+$, readily appreciable staining, distinctly marking tumour cells, and $3+$, strong staining, distinctly marking tumour cells [16]. Scoring for mTOR, STAT3 and ERK was based on modified Allred scoring guidelines for ER/PR pharmDx ${ }^{\mathrm{TM}}$ (Dako, Denmark) [22], in which the total score included a proportion score plus an intensity score; subsequently, a total score of $0-2$ was defined as 0 (negative); a total score of 3-4 was defined as $1+$ (weak staining); a total score of 5-6 was defined as $2+$ (moderate staining), and a total score above 7 was defined as $3+$ (strong staining). Finally, a two-tiered system for immunohistochemical staining was applied, i.e. 0 (negative) or $1+$ (weak staining) was considered immunonegative and 2+ (moderate staining) or $3+$ (strong staining) was considered immunopositive. Theoretically, for the leptin receptor, the presence rather than the amount of the protein is the key condition; accordingly, staining from $1+$ to $3+$ was considered immunopositive for the leptin receptor. The results for MUC2 and MUC5AC were excerpted from our previous report [6].

\section{Fluorescence in situ Hybridization}

Fluorescence in situ hybridization (FISH) was performed according to the manufacturer's protocols for 14 cases of mucinous adenocarcinoma using dual-colour Vysis kits (Abbott Molecular,
Abbott Park, Ill., USA): the HER2/CEP 17 FISH probe kit, the EGFR/CEP 7 FISH probe kit and the LSI ALK break-apart rearrangement probe. Briefly, tissues sectioned at a thickness of 1-2 $\mu \mathrm{m}$ were deparaffinized and dehydrated and then incubated in $20 \%$ sodium bisulphate $/ 2 \times$ standard saline citrate at $4^{\circ} \mathrm{C}$ for 20 min. After washing in $2 \times$ standard saline citrate, tissues were treated with proteinase $\mathrm{K}$ at $37^{\circ} \mathrm{C}$ for $25 \mathrm{~min}$. Denaturation, hybridization and washing were performed. Tissues were then counterstained with 4',6-diamidine-2'-phenylindole dihydrochloride in anti-fade solution, and examined under a fluorescence microscope (Carl Zeiss, Göttingen, Germany) equipped with a triple bandpass filter set (Abbott Molecular).

FISH results were interpreted according to recommended guidelines $[23,24]$ and the manufacturer's manual. In detail, after counting at least 20 tumour cell nuclei per case, gene amplification was defined according to the presence of tight gene clusters or to a FISH ratio (either the red signal of HER2/green signal of the centromere of chromosome 17 or the red signal of EGFR/green signal of the centromere of chromosome 7) $\geq 2$.0. In the $A L K$ FISH assay, a rearrangement with a breakpoint in the 2p23 ALK region presented single red and single green signals, whereas the native $A L K$ state presented as fused or adjacent red/green (yellow) signals. Red and green signals separated by a gap larger than two signal diameters were considered split. The occurrence of an $A L K$ rearrangement ( $A L K$ FISH positive) was diagnosed if $>15 \%$ of tumour cells exhibited split red and green signals and/or single red signals; otherwise, the specimen was classified as ALK FISH negative $[25,26]$.

\section{Statistical Analysis}

The $\chi^{2}$ test, Pearson's test and Kendall's $\tau$-b correlation analysis were used to assess correlations between protein expression and clinicopathological factors. Patient survival rates were calculated using the Kaplan-Meier method and differences in survival were compared using the log-rank test. The 'dead-of-disease' status was defined as a patient's death due to the disease itself or complications of the disease. A p value $<0.05$ was considered significant. All statistical analyses were performed using the PASW 17.0 program (SPSS Inc., Chicago, Ill., USA). 
Table 2. Clinicopathological featureas of appendiceal mucinous neoplasms $(n=56)$

\begin{tabular}{|c|c|c|c|c|}
\hline & $\begin{array}{l}\text { Total } \\
(\mathrm{n}=56)\end{array}$ & $\begin{array}{l}\text { Mucinous } \\
\text { adenoma } \\
(\mathrm{n}=22)\end{array}$ & $\begin{array}{l}\text { Mucinous neoplasm } \\
\text { of uncertain malignant } \\
\text { potential }(n=20)\end{array}$ & $\begin{array}{l}\text { Mucinous } \\
\text { adenocarcinoma } \\
(\mathrm{n}=14)\end{array}$ \\
\hline \multicolumn{5}{|l|}{ Age, years } \\
\hline Mean & 62.7 & 60.5 & 63.9 & 64.3 \\
\hline Range & $10-98$ & $10-85$ & $45-98$ & $46-87$ \\
\hline \multicolumn{5}{|l|}{ Sex } \\
\hline Male & 26 & 11 & 12 & 3 \\
\hline Female & 30 & 11 & 8 & 11 \\
\hline \multicolumn{5}{|l|}{ Clinical outcome } \\
\hline Dead of disease & 5 & 0 & 0 & 4 \\
\hline Alive with disease & 6 & 0 & 0 & 2 \\
\hline Alive without disease & 45 & 22 & 20 & 8 \\
\hline Extra-appendiceal involvement & $12^{\mathrm{a}}$ & 0 & 0 & 12 \\
\hline Pseudomyxoma peritonei & 6 & 0 & 0 & 6 \\
\hline Other organ involvement ${ }^{\mathrm{b}}$ & 10 & 0 & 0 & 10 \\
\hline
\end{tabular}

Table 3. Immunohistochemical staining results according to tumour categories

\begin{tabular}{|c|c|c|c|c|c|}
\hline Proteins & $\begin{array}{l}\text { Total } \\
(\mathrm{n}=56)\end{array}$ & $\begin{array}{l}\text { Mucinous } \\
\text { adenoma } \\
(\mathrm{n}=22)\end{array}$ & $\begin{array}{l}\text { Mucinous neoplasm } \\
\text { of uncertain malignant } \\
\text { potential }(n=20)\end{array}$ & $\begin{array}{l}\text { Mucinous } \\
\text { adenocarcinoma } \\
(\mathrm{n}=14)\end{array}$ & $p$ value \\
\hline Leptin & & & & & 0.018 \\
\hline Negative & $28(50 \%)$ & $20(91 \%)$ & $8(40 \%)$ & 0 & \\
\hline Positive & $27(50 \%)$ & $2(9 \%)$ & $12(60 \%)$ & $14(100 \%)$ & \\
\hline Leptin receptor & & & & & $\mathrm{NC}^{\mathrm{a}}$ \\
\hline Negative & 0 & 0 & 0 & 0 & \\
\hline Positive & $56(100 \%)$ & $22(100 \%)$ & $20(100 \%)$ & $14(100 \%)$ & \\
\hline MUC2 & & & & & 0.001 \\
\hline Negative & $45(80 \%)$ & $20(91 \%)$ & $20(100 \%)$ & $5(36 \%)$ & \\
\hline Positive & $11(20 \%)$ & $2(9 \%)$ & 0 & $9(64 \%)$ & \\
\hline MUC5 & & & & & 0.000 \\
\hline Negative & $50(89 \%)$ & $22(100 \%)$ & $20(100 \%)$ & $8(57 \%)$ & \\
\hline Positive & $6(11 \%)$ & 0 & 0 & $6(43 \%)$ & \\
\hline mTOR & & & & & 0.000 \\
\hline Negative & $36(64 \%)$ & $21(95 \%)$ & $9(45 \%)$ & $6(43 \%)$ & \\
\hline Positive & $20(36 \%)$ & $1(5 \%)$ & $11(55 \%)$ & $8(57 \%)$ & \\
\hline STAT3 & & & & & 0.749 \\
\hline Negative & $10(18 \%)$ & $5(22 \%)$ & $2(10 \%)$ & $3(21 \%)$ & \\
\hline Positive & $46(82 \%)$ & $17(77 \%)$ & $18(90 \%)$ & $11(79 \%)$ & \\
\hline ERK & & & & & 0.043 \\
\hline Negative & $36(64 \%)$ & $17(77 \%)$ & $13(65 \%)$ & $6(43 \%)$ & \\
\hline Positive & $20(36 \%)$ & $5(23 \%)$ & $7(35 \%)$ & $8(57 \%)$ & \\
\hline
\end{tabular}

a Not calculated statistically because the 'leptin receptor' variable is a 'constant' which has a value that always stays the same, i.e. 'positive' in all of the cases. 


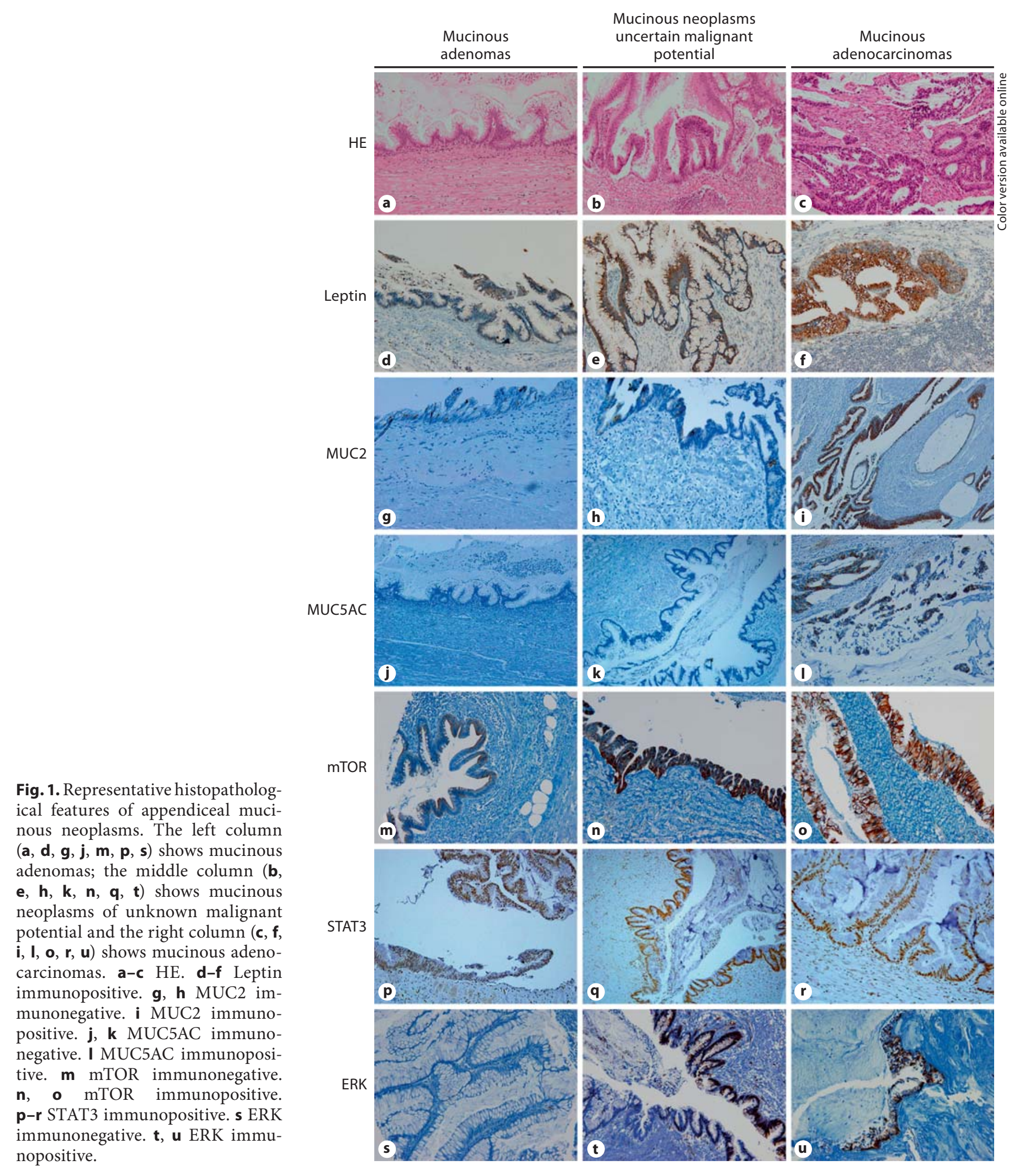

Leptin, MUC2 and mTOR in

Pathobiology 2012;79:45-53 


\section{Results}

\section{Clinicopathological Features}

The mean age of patients with 22 mucinous adenomas $(\mathrm{n}=22)$, mucinous neoplasms of unknown malignant potential $(n=20)$ and mucinous adenocarcinomas $(n=14)$ was similar and varied from 60.5 to 64.3 years (table 2). Interestingly, the number of females with mucinous adenocarcinomas was almost four times that of males. The outcome of the cases with mucinous adenocarcinoma was 'dead of disease' in 4 patients, 'alive with disease' in 2 patients and 'alive without disease' in 8 patients, whereas all patients with adenoma or mucinous neoplasms of uncertain malignant potential were 'alive without disease'. Extra-appendiceal involvement was observed in 12 of the 14 patients with mucinous adenocarcinoma. Among these 12 patients, 4 exhibited peritoneal extension beyond the right lower quadrant (pseudomyxoma peritonei) and simultaneous involvement of other organs, while 2 patients only had peritoneal extension. In each of the 10 patients showing other organ involvement, multiple organs were invaded by carcinoma: omentum in 7 , the ovary in 8 , the salpinx in 2 , the uterus in 3 , the spleen in 2 and the lymph nodes in 2 patients.

\section{Immunoexpression Status in Appendiceal Mucinous}

Neoplasms

The immunoexpression of leptin, MUC2, MUC5AC, mTOR and ERK was correlated with tumour categories, and was more frequently 'positive' in mucinous adenocarcinoma compared with mucinous adenoma and mucinous neoplasm of uncertain malignant potential $(\mathrm{p}<$ 0.05) (table 3). In particular, immunopositivity for leptin was observed in the 14 mucinous carcinomas; in contrast, the leptin signal was positive in $9 \%$ of the cases with mucinous adenoma and $60 \%$ of the cases with mucinous neoplasm of uncertain malignant potential. MUC2 was immunopositive in $64 \%$ of mucinous adenocarcinomas versus $9 \%$ of cases with mucinous adenoma and no cases of mucinous neoplasm of uncertain malignant potential. MUC5AC was immunopositive in $43 \%$ of mucinous adenocarcinomas, whereas it was immunonegative in all cases of mucinous adenoma and mucinous neoplasm of uncertain malignant potential.

The leptin receptor showed immunopositivity in the 56 appendiceal mucinous neoplasms, regardless of tumour category; in contrast, leptin receptor immunopositivity was observed in only 4 cases $(4 / 27,15 \%)$ of non-neoplastic appendiceal tissues. Similarly, STAT3 exhibited immunopositivity in $82 \%$ of tumours; more pre-

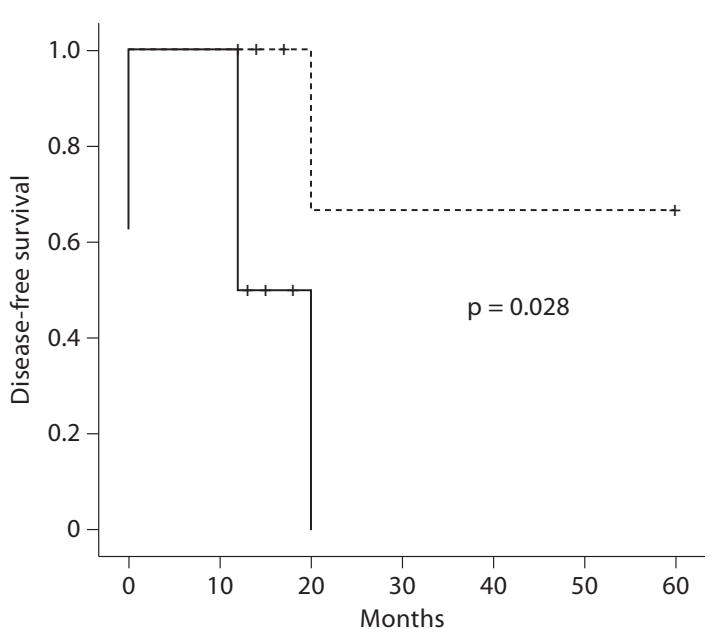

Fig. 2. Disease-free survival plots for mucinous adenocarcinoma patients, according to mTOR immunoexpression. The mTORimmunopositive group (solid line) had a shorter period of diseasefree survival compared with the mTOR-immunonegative group (dotted line) (mean, 11.5 and 46.7 months, respectively; $\mathrm{p}=0.028$ ).

cisely, $79 \%, 90 \%$ and $79 \%$ of mucinous adenoma, mucinous neoplasm of uncertain malignant potential and mucinous adenocarcinoma, respectively, were positive for STAT3, whereas all of the non-neoplastic appendiceal tissue samples were immunonegative for this protein. Moreover, all 56 appendiceal mucinous neoplasms showed immunonegativity for c-kit. Representative features of the immunoexpression results are depicted in figure 1 .

Regarding the relationship among the proteins examined in this study, leptin, mTOR and ERK were correlated with each other $(\mathrm{p}<0.05)$. Leptin was also correlated with MUC2 and MUC5AC ( $<0.05)$. In other words, leptinpositive cases were more frequently positive for mTOR, ERK, MUC2 and MUC5AC than leptin-negative cases. Additionally, MUC2-positive cases were more frequently positive for MUC5AC, than MUC2-negative cases ( $\mathrm{p}<$ 0.05). Besides, STAT3-positive cases tended to be more frequently positive for ERK than STAT3-negative cases $(p=0.06)$. As to the relationships between clinical findings and the immunoexpression of specific proteins, MUC2 was correlated with the extension of mucinous neoplasms into the peritoneum beyond the right lower quadrant (pseudomyxoma peritonei) $(\mathrm{p}<0.05)$. mTOR had a clinical impact on disease-free survival, i.e. the mTOR-positive group exhibited a lower rate and shorter 

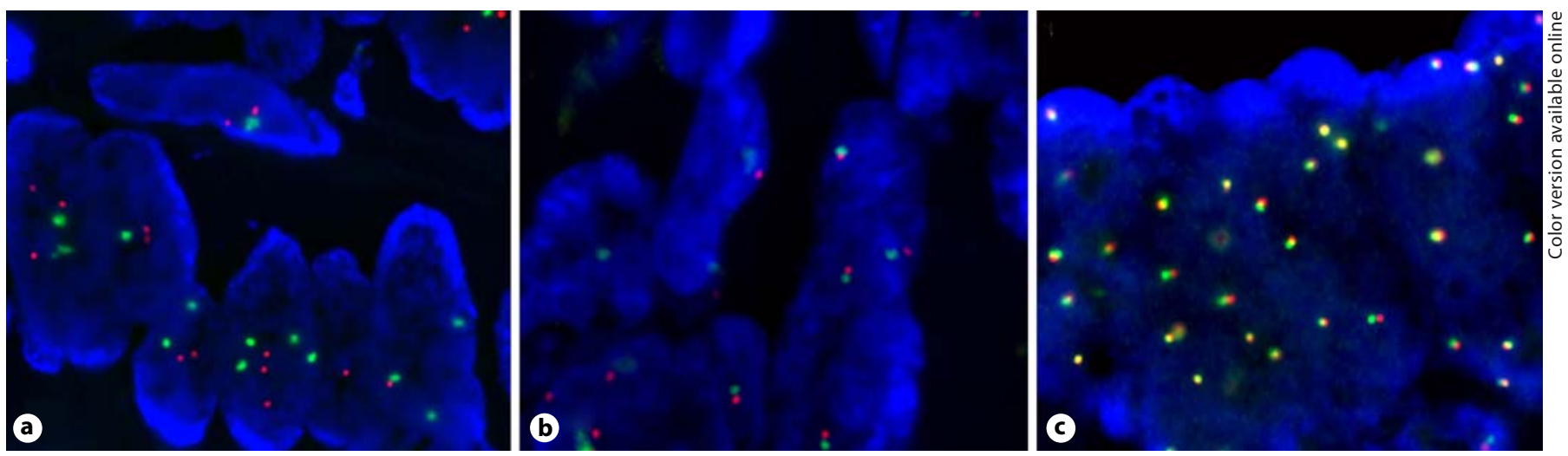

Fig. 3. FISH in appendiceal mucinous adenocarcinoma. There was no gene amplification in the tumour cells of tissues hybridized with the Her2/CEP 17 probe (a) or the EGFR/CEP 17 FISH probe (b). Gene amplification was defined as the presence of tight gene clusters or of a FISH ratio $\geq 2.0$. The FISH ratio was calculated as either a red signal of HER2/green signal of the centromere of chromosome 17, or a red signal of EGFR/green signal of the

period of disease-free survival compared with the mTORnegative group (mean, 11.5 and 46.7 months, respectively; $\mathrm{p}=0.028$ ) (fig. 2).

\section{FISH Results}

HER2/neu amplification or EGFR amplification was not observed in any of the 14 appendiceal mucinous adenocarcinomas. ALK translocation was not detected (fig. 3).

\section{Discussion}

The present study suggests that leptin, MUC2 and MUC5AC participate in the mucin-producing carcinogenesis of appendiceal mucinous neoplasms. The frequent immunopositive signals for leptin, MUC2 and MUC5AC in mucinous adenocarcinomas were in striking contrast with their low or even nil immunopositivity in mucinous adenomas or mucinous neoplasms of uncertain malignant potential, which can be useful for the diagnosis of appendiceal mucinous adenocarcinoma. In addition, leptin was correlated with MUC2 and MUC5AC ( $p<0.05)$. Recently, it has been suggested that leptin contributes to the production of mucins such as MUC2 and MUC5AC in colonic epithelial cells $[11,12]$. Thus, leptin may be involved in mucin-producing carcinogenesis as well as in mucin production.

Leptin, MUC2 and mTOR in Appendiceal Mucinous Neoplasms centromere of chromosome 7 after counting at least 20 tumour cell nuclei per case. c In tissues hybridized with an $A L K$ breakapart FISH probe, all tumour cells were $A L K$ FISH negative, i.e. had a native $A L K$ status, which shows fusion of the probes adjacent to the $3^{\prime}$ - and $5^{\prime}$-ends of the gene, labelled, respectively, with red and green fluoroprobes.

The present study indicates that leptin may function in an mTOR-, ERK- and STAT3-dependent manner in appendiceal mucinous neoplasms. All tumours showed immunopositivity for the leptin receptor, which implies that leptin may be functional as its function is mediated by the leptin receptor $[12,20]$. Moreover, leptin, mTOR and ERK were correlated with each other $(\mathrm{p}<0.05)$ and ERK was associated with STAT3, with marginal significance $(\mathrm{p}=0.06)$. These results support the contention that leptin regulates various signalling pathways involving PI3K/mTOR, ERK/MAPK and Janus family tyrosine kinase (JAK)/STAT [12, 18, 19, 21].

The present study demonstrated that JAK/STAT activation may be an early event during tumorigenesis in appendiceal mucinous neoplasms. Immunopositivity for STAT3 was observed in $82 \%$ of appendiceal mucinous tumours, $77 \%$ of mucinous neoplasms of unknown malignant potential and $90 \%$ of mucinous adenocarcinomas, whereas STAT3 was immunonegative in all non-neoplastic appendiceal tissues.

The present study showed that MUC2 may be closely connected with pseudomyxoma peritonei and that MUC2 may be a target for molecular therapy in this condition. Patients exhibiting immunopositivity for MUC2 were affected with pseudomyxoma peritonei more frequently compared with MUC2-negative patients $(\mathrm{p}<0.05)$. This result is consistent with the results of previous reports. In 2002, O'Connell et al. [8] demonstrated that MUC2 served as a reliable molecular marker of pseudomyxoma 
peritonei. In 2008, Semino-Mora et al. [10] reported that the expression of MUC2 was drastically higher in peritoneal-free mucin and in mucinous neoplastic epithelia of pseudomyxoma peritonei compared with non-neoplastic appendiceal epithelia; additionally, these authors found that multiple enteric bacteria were present in pseudomyxoma peritonei and that bacterial density and MUC2 expression were higher in peritoneal-free mucin of pseudomyxoma peritonei compared with controls. In vitro experiments showed that the MUC2 gene is upregulated by lipopolysaccharides of Gram-negative bacteria [27].

The present study implies that mTOR may be a putative target for molecular therapy in appendiceal mucinous adenocarcinomas. mTOR exhibited higher immunopositivity in patients with appendiceal mucinous adenocarcinoma. Furthermore, mTOR was clinically significant as the disease-free survival period of the mTORpositive group was longer than that of the mTOR-negative group (mean, 11.5 and 46.7 months, respectively; $\mathrm{p}=$ 0.028). A recent article reviewed a clinical trial of $\mathrm{mTOR}$ inhibitors (rapamycin and its analogues) for the treatment of several kinds of malignancy; moreover, the effi- cacy of mTOR inhibition in the treatment of various types of cancer is currently being evaluated [28]. In contrast, other candidates for molecular therapy such as $c$ kit, HER2, EGFR and ALK were unfit as targets. In other words, all adenocarcinoma cases showed immunonegativity for c-kit, no cases exhibited HER2/neu or EGFR amplification, and no cases had $A L K$ translocation.

In conclusion, leptin may cooperate with MUC2 and MUC5AC in the development of mucin-producing carcinogenesis in appendiceal mucinous adenocarcinomas, which may occur in an mTOR-, STAT- and ERK-dependent manner. The MUC2 gene is a putative target for molecular therapy of pseudomyxoma peritonei. Finally, mTOR (but not c-kit, Her2, EGFR or ALK) may represent a target for the molecular therapy of appendiceal mucinous adenocarcinoma.

\section{Acknowledgement}

This work was supported by the Seoul National University Boramae Hospital Grant.

\section{References}

1 Collins DC: 71,000 human appendix specimens, a final report summarizing forty years' study. Am J Proctol 1963;4:265-281.

2 Carr NJ, McCarthy WF, Sobin LH: Epithelial noncarcinoid tumours and tumour-like lesions of the appendix. A clinicopathological study of 184 patients with a multivariate analysis of prognostic factors. Cancer 1995; 75:757-768.

-3 Misdraji J, Yantiss RK, Graeme-Cook FM, Balis UJ, Young RH: Appendiceal mucinous neoplasms: a clinicopathological analysis of 107 cases. Am J Surg Pathol 2003;27:10891103.

-4 Pai RK, Longacre TA: Appendiceal mucinous tumours and pseudomyxoma peritonei: histologic features, diagnostic problems, and proposed classification. Adv Anat Pathol 2005; 12:291-311.

5 Carr NJ, Sobin LH: Adenocarcinoma of the appendix; in Bosman FT, Carneiro F, Hruban RH, Theise ND (eds): World Health Organization classification of the digestive system, ed 4. Lyon, IARC Press, 2010, pp 119125.

-6 Yoon SO, Kim BH, Lee HS, Kang GH, Kim WH, Kim YA, Kim JE, Chang MS: Differential protein immunoexpression profiles in appendiceal mucinous neoplasms: a special reference to classification and predictive factors. Mod Pathol 2009;22:1102-1112.
-

Young RH: Pseudomyxoma peritonei and selected other aspects of the spread of appendiceal neoplasms. Semin Diagn Pathol 2004; 21:134-150.

8 O'Connell JT, Tomlinson JS, Roberts AA, McGonigle KF, Barsky SH: Pseudomyxoma peritonei is a disease of MUC2-expressing goblet cells. Am J Pathol 2002;161:551-564.

9 Misdraji J: Appendiceal mucinous neoplasms: controversial issues. Arch Pathol Lab Med 2010;134:864-870.

10 Semino-Mora C, Liu H, McAvoy T, Nieroda C, Studeman K, Sardi A, Dubois A: Pseudomyxoma peritonei: is disease progression related to microbial agents? A study of bacteria, MUC2 AND MUC5AC expression in disseminated peritoneal adenomucinosis and peritoneal mucinous carcinomatosis. Ann Surg Oncol 2008;15:14141423.

11 Plaisancié P, Ducroc R, El Homsi M, Tsocas A, Guilmeau S, Zoghbi S, Thibaudeau O, Bado A: Luminal leptin activates mucin-secreting goblet cells in the large bowel. Am J Physiol Gastrointest Liver Physiol 2006; 290:G805-G812.
12 El Homsi M, Ducroc R, Claustre J, Jourdan G, Gertler A, Estienne M, Bado A, Scoazec JY, Plaisancié P: Leptin modulates the expression of secreted and membrane-associated mucins in colonic epithelial cells by targeting PKC, PI3K, and MAPK pathways. Am J Physiol Gastrointest Liver Physiol 2007; 293:G365-G373.

13 Pelleymounter MA: Cullen MJ, Baker MB, et al: Effects of the obese gene product on body weight regulation in ob/ob mice. Science 1995;269:540-543.

14 Gao J, Tian J, Lv Y, Shi F, Kong F, Shi H, Zhao L: Leptin induces functional activation of cyclooxygenase-2 through JAK2/STAT3, MAPK/ERK, and PI3K/AKT pathways in human endometrial cancer cells. Cancer Sci 2009;100:389-395.

15 Uddin S, Bavi PP, Hussain AR, Alsbeih G, Al-Sanea N, Abduljabbar A, Ashari LH, Alhomoud S, Al-Dayel F, Ahmed M, Al-Kuraya KS: Leptin receptor expression in Middle Eastern colorectal cancer and its potential clinical implication. Carcinogenesis 2009; 30:1832-1840.

16 Riolfi M, Ferla R, Del Valle L, Piña-Oviedo S, Scolaro L, Micciolo R, Guidi M, Terrasi M, Cetto GL, Surmacz E: Leptin and its receptor are overexpressed in brain tumours and correlate with the degree of malignancy. Brain Pathol 2010;20:481-489. 
- 17 Hursting SD, Berger NA: Energy balance, host-related factors, and cancer progression. J Clin Oncol 2010;28:4058-4065.

18 Sweeney G: Leptin signalling. Cell Signal 2002;14:655-663.

-19 Saxena NK, Sharma D, Ding X, Lin S, Marra F, Merlin D, Anania FA: Concomitant activation of the JAK/STAT, PI3K/AKT, and ERK signaling is involved in leptin-mediated promotion of invasion and migration of hepatocellular carcinoma cells. Cancer Res 2007;67:2497-2507.

20 Kim HS: Leptin and leptin receptor expression in breast cancer. Cancer Res Treat 2009; 41:155-163.

-21 Saxena NK, Vertino PM, Anania FA, Sharma D: Leptin-induced growth stimulation of breast cancer cells involves recruitment of histone acetyltransferases and mediator complex to CYCLIN D1 promoter via activation of Stat3. J Biol Chem 2007;282:1331613325.
-22 Hammond ME, Hayes DF, Dowsett M, Allred DC, Hagerty KL, Badve S, Fitzgibbons PL, Francis G, Goldstein NS, Hayes M, Hicks DG, Lester S, Love R, Mangu PB, McShane L, Miller K, Osborne CK, Paik S, Perlmutter J, Rhodes A, Sasano H, Schwartz JN, Sweep FC, Taube S, Torlakovic EE, Valenstein P, Viale G, Visscher D, Wheeler T, Williams RB, Wittliff JL, Wolff AC; American Society of Clinical Oncology; College of American Pathologists: American Society of Clinical Oncology/College of American Pathologists guideline recommendations for immunohistochemical testing of estrogen and progesterone receptors in breast cancer. J Clin Oncol 2010;28:2784-2795.

23 Cappuzzo F, Hirsch FR, Rossi E, Trisolini R, Paioli D, Magrini E, Finocchiaro G, Bartolini S, Cancellieri A, Hirsch FR, Crino L, Varella-Garcia M: Epidermal growth factor receptor gene and protein and gefitinib sensitivity in non-small-cell lung cancer. J Natl Cancer Inst 2005;97:643-655.

$\checkmark 24$ Wolff AC, Hammond ME, Schwartz JN, Hagerty KL, Allred DC, Cote RJ, Dowsett M, Fitzgibbons PL, Hanna WM, Langer A, McShane LM, Paik S, Pegram MD, Perez EA, Press MF, Rhodes A, Sturgeon C, Taube SE, Tubbs R, Vance GH, van de Vijver M, Wheeler TM, Hayes DF; American Society of Clinical Oncology/College of American Pathologists: American Society of Clinical Oncology/College of American Pathologists Guideline Recommendations for Human Epidermal Growth Factor Receptor 2 Testing in Breast Cancer. Arch Pathol Lab Med 2007; 131:18-43.
25 Rodig SJ, Mino-Kenudson M, Dacic S, Yeap BY, Shaw A, Barletta JA, Stubbs H, Law K, Lindeman N, Mark E, Janne PA, Lynch T, Johnson BE, Iafrate AJ, Chirieac LR: Unique clinicopathologic features characterize ALK-rearranged lung adenocarcinoma in the western population. Clin Cancer Res 2009; 15:5216-5223.

-26 Camidge DR, Kono SA, Flacco A, Tan AC, Doebele RC, Zhou Q, Crino L, Franklin WA, Varella-Garcia M: Optimizing the detection of lung cancer patients harboring anaplastic lymphoma kinase (ALK) gene rearrangements potentially suitable for ALK inhibitor treatment. Clin Cancer Res 2010;16:55815590.

27 Dohrman A, Miyata S, Gallup M, Li JD, Chapelin C, Coste A, Escudier E, Nadel J, Basbaum C: Mucin gene (MUC 2 and MUC 5AC) upregulation by Gram-positive and Gram-negative bacteria. Biochim Biophys Acta 1998;1406:251-259.

-28 Easton JB, Houghton PJ: mTOR and cancer therapy. Oncogene 2006;25:6436-6446. 